\title{
Supervisor-Subordinate Communication Relationships, Role Ambiguity, Autonomy and Affective Commitment for nurses
}

Yvonne Brunetto BA, DipED, PhD

Associate Professor in HRM

School of Commerce and Management,

Southern Cross University

P.O Box 42, Tweed Heads,

NSW. 2485 AUSTRALIA

ph: +61255069373

Fax: +61255069370

Email: yvonne.brunetto@scu.edu.au

Rod Farr-Wharton B.Sc, M.Sc. PhD

University of the Sunshine Coast,

Maroochydore, Queensland. 4558, AUSTRALIA

Ph: +61 754301217

Email: rfarr@usc.edu.au

Kate Shacklock B.Ec, PhD

Department of Employment Relations and Human Resources,

Griffith University - Gold Coast campus

Southport 4215, Queensland, AUSTRALIA

ph: +61 755528543

Fax: +61 755529206

Email: k.shacklock@griffith.edu.au

\section{Correspondence:}

k.shacklock@griffith.edu.au 


\section{Supervisor-Subordinate Communication Relationships, Role Ambiguity, Autonomy and Affective Commitment for nurses}

Aim: This paper examined nurses' levels of satisfaction with their supervisorsubordinate communication relationships on their level of role ambiguity (in relation to their supervisors) and their resultant perceptions of autonomy and in turn, affective commitment

Methods: A survey of 900 nurses working in private sector hospitals in Australia was used to collect data.

Results: The combined effects of supervisor-nurse communication relationships, nurses' role ambiguity in relation to their supervisors plus nurses' resultant perceptions of autonomy, definitely influenced nurses’ level of affective commitment. Also, nurses were somewhat dissatisfied with their communication relationships with their supervisors, experienced role ambiguity, reported being only a little autonomous, and were subsequently only somewhat committed to their hospitals.

Contribution: The findings contribute to addressing nurse retention challenges by identifying factors affecting nurses' organisational commitment. Not only will nurses be more productive (with less supervisor ambiguity), but high quality NUM-nurse communication relationships are also likely to enhance perceptions of autonomy and thereby, encourage nurses’ commitment to their organisation and intention to remain. Implications: These results raise the question as to whether the present management practices are ideal for retaining nurses who are in short supply in many Organisation for Economic Co-operation and Development countries.

Keywords: nurses, Leader Member Exchange Theory, autonomy, role ambiguity in relation to supervisors, affective commitment 


\section{Supervisor-subordinate Communication Relationships, Role Ambiguity, Autonomy and Affective Commitment for nurses}

This paper uses a Leader-Member Exchange (LMX) theoretical framework to examine the impact of recent reforms affecting the supervisor-subordinate communication relationship on the organisational outcomes of Australian nurses. Over the past few decades, reforms have been implemented to increase the accountability of nurses and the task of monitoring them has been left to supervisors (called Nurse Unit Managers - NUMs) (Buchanan and Considine 2002; Neuman, Maylor and Chansarkar 2002), in turn, influencing how supervisors communicate (Brunetto and Farr-Wharton, 2007). As a result of reforms, NUMs are now expected to monitor, measure and assess the performance of nurses to a far greater extent (Ackroyd, Kirkpatrick and Walker, 2007; Ferlie, Ashburner, Fitzgerald and Pettigrew 1996; Kirkpatrick and Ackroyd, 2003). This has likely changed the nature of the supervisor-subordinate communication relationship in turn, affecting other outcomes (Brunetto and Farr-Wharton, 2006). Hence, this study uses a leader-member exchange (LMX) theoretical lens to examine the organisational outcomes for nurses based on the quality of their NUM-nurse communication relationship.

LMX theory argues that under perfect conditions effective workplace relationships especially the supervisor-subordinate relationship leads to benefits for both the individual and the organisation. In particular, the theory argues that supervisors manage employees differently and consequently, some employees experience high levels of trust, respect and mutual support which helps them to solve problems in the workplace efficiently and effectively whereas other employees experience the opposite work conditions (Gerstner and Day 1997; Mueller and Lee 2002). 
Nurses in countries such as the UK, NZ and Australia have experienced 'increasing bureaucracy and managerial supervision... leading to shifts in the nature and quantity of work' (Ackroyd, et al., 2007: 18). This is likely to have affected nurses’ satisfaction with supervision (and subsequent communication from them) and in turn, this may have negatively affected level of supervisor ambiguity. Consequently, this paper examines the impact of nurses' level of satisfaction with their supervisorsubordinate communication relationships on their level of role ambiguity (in relation to their supervisors) and their resultant perception of autonomy and in turn, affective commitment. Affective commitment is used as a measure of organisational outcomes because it is a predictor of absenteeism and turnover (Eby, Adam, Russell and Gaby, 2000) as well as organisational effectiveness (Judge and Watanabe 1993; Pitt, Leyland, Foreman and Bromfield, 1995; Meyer and Herscovitch, 2001). This is a major concern for nurses because they are in short supply in many Organisation for Economic Co-operation and Development (OECD) countries and management practices have been identified as a major factor affecting turnover (Fitzgerald, 2002). The following primary research question (PRQ) guides the study: What is the impact of the supervisor-subordinate communication relationship upon nurses' perceptions of role ambiguity (in relation to supervisors) and in turn, their perceptions of autonomy and affective commitment?

This paper has three parts. The first part provides a targeted review of the literature from which the hypotheses emerge. The second part describes the sample and methods use to test the hypotheses and address the research question. The third part reports the results followed by the discussion section, which identifies patternmatching with relevant past research, implications for hospital managers and healthcare policymakers, and limitations of the research. 


\section{LMX Theory}

As stated, the main assumption of LMX theory is that employees are managed differently by supervisors, and as a result, some have good work outcomes and some do not. A positive supervisor-subordinate relationship develops when employees experience high quality 'social exchanges' over a sustained period, (Graen and UhlBien, 1995). The 'in-group' employees receive mutual support, trust and respect and increased access to information, support and participation in decision-making, which in turn, makes it easier for them to undertake tasks and solve work-related problems (Gerstner and Day 1997; Mueller and Lee 2002). They are also consequently more likely to be promoted, receive bonuses, get interesting work assignments and have control over workloads. The benefits for the supervisor are loyalty and esteem as well as the knowledge and satisfaction of knowing that they influence the behaviour and practices of subordinates (Basu and Green, 1995). On the other hand, the 'out-group' experiences the opposite workplace situation.

Using the LMX theoretical lens, an ideal situation is when NUMs facilitate an effective flow of information within an empowering relationship where nurses have access to their NUM's time (Sparrowe and Linden, 1997). Moreover, nurses receive meaningful feedback and are empowered to make decisions (Wayne, et al., 1997; Yrie, Hartman, and Galle, 2003). When this happens, the greatest benefits are delivered to nurses, patients and the hospital. Hence, using LMX theory, it seems likely that the quality of NUM-nurse communication relationship could affect their perceptions of role ambiguity about NUMs, particularly in relation to what they expect of them, which in turn is likely to affect their perceptions of autonomy. In combination, these factors are likely to either positively or negative impact upon nurses' levels of affective commitment. In contrast, poor conditions for achieving 
clarity for nurses involve getting mixed messages from their NUMs - some empowering nurses to make workplace decisions and others reducing their perception of autonomy/discretionary power to make workplace decisions. These contradictory messages negatively impact on nurses' perception of autonomy, and this may in turn affect their commitment to their hospital. The next section reviews relevant literature related to the concepts: supervisor-subordinate communication relationship, autonomy and affective commitment.

\section{Supervisor-Subordinate Communication Relationship}

The supervisor-subordinate communication relationship is a function of the quality and quantity of social interactions which can be examined in terms of four communication constructs. When effective supervisor-subordinate communication relationships are embedded within established management practices and processes, then trust and harmony builds within the working relationships (Mayfield and Mayfield, 2002). When these conditions exist, the outcomes are greatest for both the employee and the organisation (Gray and Laidlaw 2002).

Jolke and Duhan (2000) argue that one way of capturing the quality of the supervisorsubordinate communication relationship is to examine the frequency, mode, content and flow of communication. Frequent interactions between supervisors and subordinates provide the first building block for developing an effective supervisorsubordinate (Kacmar, Witt, Zivnuska and Gully 2003). However, the second building block affecting the development of effective supervisor-subordinate relationship depends on the mode of communication. If formal communication processes (such as organisational documents and manuals) are used, then social capital will build slowly. However, if informal communications (such as conversations in the hallway) are used then the quality of the workplace relationship between supervisors and subordinates 
improves (Jolke and Duhan 2000, 2001). Employees rely on the unofficial informal means of communication to fill in the holes of information that supervisors fail to tell subordinates, but that supervisors need to know in order to survive in an organisation (Goris, Vaught and Pettit 2000).

Similarly, the third building block depends on the directness of communication practices. When indirect communication strategies are used it means that supervisors are using empowering management practices, give lots of feedback, are open to ideas and are prepared to listen to subordinates' concerns.. In contrast, when supervisors use their hierarchical power to dictate orders and invoke a power barrier between themselves and their subordinates, then, the impact of such direct communication strategy is to stifle the development of an effective supervisor-subordinate relationship (Fisher, Maltz and Jaworski 1997). The fourth communication process affecting the quality of supervisor-subordinate relationships is the quality of communication flow (between supervisors and subordinates). When the communication between supervisors and subordinates flow, it means that employees are able to ask for clarification or assistance in solving workplace problems (Gray and Laidlaw 2002). In summary, when communication theory is applied to the nursing context, effective high quality NUM-nurse relationships are enhanced when there are frequent informal communications episodes using indirect means that facilitate bidirectional communication between the NUMs and their nurses.

\section{Role Ambiguity/Clarity - Supervisor Ambiguity}

Role clarity is the opposite of role ambiguity and refers to a situation where employees know what their supervisors expect of them in the workplace. This process is facilitated positively by an effective supervisor-subordinate relationship and thwarted when employees receive conflicting messages from subordinates - perhaps 
empowering them in some work situations and disempowering them in similar situations at a different time (Jolke and Duhan 2000). The ambiguity is unlikely to facilitate the openness required for subordinates to feel comfortable enough to ask questions when required when solving a work related problem. In contrast, when subordinates experience an effective subordinate-supervisor communication relationship, they are likely to experience greater role clarity in relation to the supervisor. When this information is applied to the nursing context, nurses are more likely to experience role clarity in relation to their NUMs when the messages they receive from NUMs are consistent and similar in substance. Consequently, it is expected that there will be an inverse relationship between nurses' level of satisfaction with their NUM-nurse communication relationship and their level of role ambiguity in relation to supervisors. To test this premise, the following hypothesis is suggested:

Hypothesis 1: There is a significant inverse relationship between nurses' satisfaction with supervisor-subordinate communication relationships and their perceptions of role ambiguity (in relation to the supervisor).

\section{Autonomy}

Autonomy is embedded within the empowerment construct. Spreitzer (2007) identifies two conceptualisations of empowerment. Specially, structural empowerment is defined as the organisational structures and processes that facilitate optimal employee performance and psychological empowerment is defined as employees' responses to working within a particular organisational empowerment context. In particular, structural empowerment theory argues that organisations determine the quality of structural empowerment experienced by employees by 
influencing their access to resources, information, guidance and support (Kanter, 1977).

The quality of structural empowerment is manifested in employees' perception of psychological empowerment (Seibert, Silver and Randolph, 2004). In particular, psychological empowerment has been conceptualised as: 'meaning', 'competence', 'self-determination' and 'impact'. Meaning refers to a work goal moderated against an employee's own beliefs and values. Competence refers employees' level of selfefficacy about their capabilities to undertake tasks), Self-determination refers to employees' sense of autonomy about workplace choices. Impact refers to employees’ beliefs about their impact in the workplace (Spreitzer, 1995, 1996).

Nurses are similar to other professionals in having some level of discretionary power/autonomy because of their specific knowledge. Moreover, being a professional means that nurses have a relatively high level of personal autonomy because of the specific skills and extensive education and training required to be a professional (Ferlie et al., 1996). Based on the Anglo-American model, professionals are those employees who are eligible to belong to professional associations that work with universities and the government to control the number of employees gaining the skills and accreditation into the profession (Evetts and Buchner-Jeziorska, 1997). In the case of nurses, some countries such as the UK, do not have a requirement for a formal university qualification, however, there are many countries that do have that requirement, and moreover, there is an increasing trend towards more nurses gaining professional qualifications (Robinson, Murrells and Clinton, 2006).

Using LMX theory, nurses would feel most autonomous when they have clarity in the messages coming from their supervisors and therefore would clearly understand their work tasks and know who to contact for support and/or expert clinical 
knowledge/advice required for addressing the needs of their patients. The following hypothesis is proposed to test this premise:

Hypothesis 2: There is a significant positive relationship between nurses' perceptions of role clarity (in relation to the supervisor) and their level of autonomy.

\section{Affective Commitment}

Affective commitment refers to the emotional attachment to, and identification with, an organisation (Allen and Meyer, 1990). Gerstner and Day (1997) have previously identified a significant relationship between supervisor-subordinate communication relationships and affective commitment. Other researchers have linked supervisorsubordinate relationships with affective commitment (loyalty and attachment to the firm) and turnover intentions (Meyer and Allen 1997; Pitt, Leyland, Foreman and Bromfield, 1995). In the case of nurses, the issue of commitment is vital because they are in short supply in many OECD countries (OECD, 2005; PC, 2005) and governments in numerous OECD countries have been developing specific policies aimed at importing, recruiting and retaining them.

Moreover, poor management practice has been identified as one factor contributing to the nurse retention problem (Brunetto, Farr-Wharton and Shacklock, 2010; Buchan and Calman, 2004). In response, the US (and to a lesser extent, Australia) has had some success in implementing the 'Magnet Hospital' management model, which has as one of its cornerstones the re-empowering of nurses as a means of retaining them (Buchan, 1999; Laschinger and Wong, 1999). The healthcare sector has undergone constant reform implementation and often those reforms have aimed to reduce the autonomy of professionals such as nurses (Brunetto, Farr-Wharton and Shacklock, 2011). Hence, Ackroyd, Kirkpatrick and Walker $(2007,10)$ argue that supervision is 
pivotal in determining the power and autonomy of professionals such as nurses because they affect how reforms are communicated and implemented, which in turn, affects the extent to which nurses resist or adopt reforms, and it is argued that this has in turn, affected the commitment of nurses to their ward and hospital. To guide the data collection, the following hypotheses are proposed:

Hypothesis 3: There is a significant positive relationship between nurses' perception of autonomy and their levels of affective commitment.

Hypothesis 4: There is a significant positive relationship between nurses' satisfaction with supervisor-subordinate communication relationships, their perceptions of role clarity (in relation to the supervisor) and discretionary power/autonomy and their levels of affective commitment.

\section{METHODS}

This research uses a cross-sectional design to gather data in order to test whether the quality of supervisor-subordinate communication relationships, level of role ambiguity in relation to supervisors; perception of autonomy and affective commitment for nurses Data were collected from 900 nurses working in private sector hospitals in Australia using a survey-based, self-report strategy (Ghauri and Gronhaug, 2002). The emerging patterns of data were then compared with the findings of previous research.

\section{Measures}

The measures were generated from the extant literature, and all item statements were rated using a 6-point Likert-type scale, with $1=$ strongly disagree, ranging to $6=$ strongly agree. The measures comprised: 
1. The satisfaction of supervisor-subordinate communication relationship, which was operationalised by developing one combined measure using 10 items from Jolke and Duhan's (2000) subscales measuring employees’ satisfaction with the frequency of communication (number of contacts), the mode of communication (formal informal means), the direction of communication (direct or indirect) and the flow of communication (two-way or mostly oneway from supervisor to employee). The Chronbach’s alpha coefficient was .803 and one item was, 'I often discuss my work with my NUM'.

2. Role Ambiguity in relation to supervisors was operationalised using Jolke and Duhan's (2000) 3-item measure. The Chronbach’s alpha coefficient was .905 and one item was, 'I am certain how satisfied my NUM is with me'.

3. Autonomy (discretionary power) was operationalised using Spreitzer's (1996) 4-item measure of self-determination. The Chronbach’s alpha coefficient was .895 and one item was, 'I can decide on my own how to go about doing my work'.

4. Allen and Meyer's (1990) 4-item commitment instrument was used to measure the dependent variable - affective commitment (commitment to the organisation) - using 8 items. The Chronbach’s alpha coefficient was .87 and one item was, 'I feel a strong sense of belonging to this hospital'.

\section{Sample}

Nurses in Australia service patients within both public and private hospitals. This is because public sector providers provide approximately 60 percent of hospital beds leaving $40 \%$ to be provided by the private sector and non profit organisations (Gee, 2007). Sampling choices were made based to ensure representation of:

1. Urban and regional hospitals 
2. Big (metropolitan), medium and smaller hospitals

To gather data from a range of ward nurses, including registered, enrolled and endorsed enrolled nurses, 4,500 anonymous surveys were distributed to 7 private sector hospitals chosen to meet the above criteria. The response was 900 useable surveys - a response rate of $20 \%$.

\section{Analysis of the Surveys}

Correlation coefficients and regression analyses were undertaken to test the first three hypotheses and path analysis was used to test the impact of supervisor-subordinate communication relationship on nurses' perceptions of role ambiguity in relation to supervisors, then autonomy and affective commitment. In particular, path analysis using an ordinary least square (OLS) approach is used to test the last hypothesis. OLS is an explanation of variance and the overall $\mathrm{R}^{2}$ measure identifies the goodness of fit overall for the proposed model (Ahn, 2002). The advantage of path analysis is that it permits more than one equation to predict the dependent variable (i.e. affective commitment) and therefore it includes the indirect impact of supervisor-subordinate communication relationship into the bigger equation. The OLS approach also estimates parameters within an independent system, which could avoid the problem of multicollinearity (Grapentine, 2000).

\section{Ethical considerations}

Ethics approval was gained from the university and hospital ethics committees.

Voluntary participation was explained in the cover sheet to the survey and contact details of the researchers were provided in case of queries.

\section{RESULTS}


The sample comprised 33 males and 867 females, with 74 respondents aged less than thirty years, 340 aged between 30 and 45 years and 486 aged over forty-five years. Within the nursing sample, 55 were Nurse Unit Managers (NUM), 738 were Registered Nurses (RN), and 107 were Enrolled Nurses (EN).

[Insert Table 1 here]

\section{Factor Analysis}

The correlation matrix identified many correlations exceeding .3, indicating the matrix was suitable for factoring. The Bartlett's test for Sphericity was significant (Chi-square value $=12421.094, \mathrm{p}<.001 . \mathrm{df} 190)$ and the Kaiser-Meyer-Olkin $(\mathrm{KMO})$ measure of sampling adequacy was .901 - well above the .6 requirement. When Principal Axis Factoring was undertaken to extract the variables, four factors had eigenvalues greater than one and $64.389 \%$ of the variance could be explained using these four factors. The factor transformation matrix suggests a relatively high correlation between factors. As stated, the advantage of using an OLS approach can avoid the problem of multicollinearity.

\section{Correlation Matrix}

Table 2 details the correlation coefficients for each variable. All variables were significantly related to one another except for the control variable - location. The Cronbach's Alpha scores measuring reliability ranged from 0.803 to 0.905 .

[Insert Table 2 here]

\section{Results from statistical analysis}

Hypothesis 1: A linear regression was undertaken and the results support the hypothesis proposed. The data showed that $61.4 \%$ of the role ambiguity in relation to the supervisor can be explained by the variance of the supervisor-subordinate 
communication relationship. Moreover, an analysis of the means suggests that the relationship is inverse with the lower nurses level of satisfaction with supervisor communication, the greater the level of perceived ambiguity about the messages received (See Table 3).

\section{[Insert Table 3 here]}

Hypothesis 2 A linear regression analysis was undertaken and the results support the hypothesis proposed. The data showed that $7.6 \%$ of the variance of autonomy can be explained by supervisor ambiguity (See Table 4).

\section{[Insert Table 4 here]}

Hypothesis 3 A linear regression was undertaken and the results support the hypothesis proposed. The data showed that $11.6 \%$ of the variance of affective commitment can be explained by nurses' perception of autonomy (See Table 5). An examination of the means for both variables suggests a direct positive relationship with the higher the mean, the higher the resultant level of affective commitment.

\section{[Insert Table 5 here]}

Hypothesis 4 Path analysis using regressions was undertaken and the results support the hypothesis proposed. The data showed that approximately a quarter (24.6\%) of the variance of nurses' affective commitment can be explained by supervisor communication, supervisor ambiguity and discretionary power. These findings suggest that these factors are indeed important in determining the commitment of nurses to a hospital (See Table 6).

\section{[Insert Table 6 here]}

\section{DISCUSSION}

This paper examined four important nurse management issues: supervisor-subordinate communication relationships, supervisor ambiguity/clarity, autonomy and affective 
commitment, plus the relationship between them. A summary of the literature suggests that the implementation of management reforms was supposed to improve organisational processes such as supervision. However, the findings suggest that nurses have somewhat low levels of satisfaction with supervisor-subordinate communication relationship and not surprisingly, they experienced somewhat high levels of role ambiguity in relation to the supervisors, although supervisor ambiguity in itself was not a significant factor influencing the affective commitment of nurses.

Moreover, nurses experienced relatively low levels of autonomy, particularly for a professional group. Previous research suggests that nurses are relatively autonomous because of their expert knowledge (Larson, 2005). However, these findings provide further evidence that healthcare reforms have reduced the power of nurses by increasing the power of NUMs to monitor and make nurses more accountable for tasks. This has probably contributed to nurses' perceptions of being only somewhat autonomous, supporting earlier research by Ackroyd, et al (2007) and Ferlie et al (2006). In contrast, the LMX literature suggests that best management practices involve empowering relationships for employees (Spritzer, 1995, 1996), yet these findings are not consistent with nurses operating in such empowering workplaces.

The fourth concept examined the affective commitment of nurse. The findings suggest that nurses are only somewhat committed to their organisation. This has important consequences because nurses are in short supply in numerous OECD countries. This is a problem for the public in general, plus governments and hospital managers, because of the high costs of training and replacing nurses as well as the consequences of reduced health provision, and especially when hospitals wards could be closed because of the lack of trained staff. It is therefore imperative that researchers identify factors affecting nurses’ levels of organisational commitment, not 
only because they affect their productive potential, but also because they are predictors of turnover (Palese, Pantali and Saiani, 2006). This study has identified that less than ideal NUM-nurse communication relationships, coupled with role ambiguity (in relation to supervisors) and perceptions of low levels of autonomy, do significantly impact upon nurses' affective commitment. In this case, using the OLS procedure, the 'goodness of fit' identified that these three factors (supervisorsubordinate communication relationship, role ambiguity/clarity and autonomy) accounted for a quarter of the variance of nurses' levels of affective commitment. That is, for nurses, the quality of supervisor-subordinate communication relationships is important because it not only contributes to supervisor ambiguity and perceptions of discretionary power, but also because it is significantly positively related to affective commitment. Hence, the findings suggest that nurses require a change in supervision practices so as to improve supervisor-subordinate communication relationships, which in turn, could enhance (rather than compromise) their perceptions of supervisor clarity and thereby, discretionary power. It seems likely that nurses' present low levels of satisfaction with NUM-nurse communication relationships, plus lower perceptions of supervisor clarity and discretionary power have negatively affected their commitment to their hospitals.

The findings build on previous knowledge about nurses and provide new understanding about how supervisor-subordinate communication relationships affect nurses' perceptions of supervisor ambiguity and discretionary power and thereby, affective commitment. As such, this paper contributes new knowledge about the impact of supervisor-subordinate communication relationships, supervisor ambiguity and the discretionary power of nurses upon affective commitment. Because past research has already established a significant positive relationship between the quality 
of supervisor-subordinate relationships and organisational effectiveness (Gerstner and Day, 1997), it seems unlikely that the present conditions are ideal for achieving organisational effectiveness in these hospitals. Of greater importance, these same conditions appear less than optimum for retaining nurses - particularly those who are well-trained and in high demand, because nurses who report dissatisfaction with management policies and practices have a $65 \%$ higher intention to quit than those reporting satisfaction (Gray and Phillips, 1994; Secombe and Smith, 1997). Therefore, this paper contributes to the wider contemporary debate about the importance of improving organisational processes affecting supervisor-subordinate communication relationships, supervisor ambiguity/clarity and discretionary power because they affect levels of affective commitment.

\section{Limitations}

This study has a number of limitations. The main limitations are the fairly low response rate of $20 \%$ and the use of self-report surveys causing common methods bias. However, Spector (1994) argues that self-reporting methods is legitimate for gathering data about employees' perceptions, as long the instrument reflects an extensive literature review and pattern-matching is used to support interpretations of the data and triangulation is used to support research findings.

Other limitations are the use of only private sector hospitals, plus the predominance of females in the nursing sample. Further studies exploring public sector hospital nurses and the impact of gender in similar circumstances may be worthwhile, because past research (ABS, 2009) has identified differences in workforce participation for men and women, possibly affecting the development of effective supervisorsubordinate communication relationships.

\section{Implications}


Nurses were somewhat unsatisfied with their supervisor-subordinate communication relationships, experienced some level of role ambiguity in relation to their supervisor, and perceived themselves to be only somewhat autonomous (Larson, 2005). The implication of low levels of nurse satisfaction with supervisor-subordinate communication relationships is that nurses appear to operate in work contexts that provide frustrations to their optimum performance. Such organisational conditions are unlikely to stem the flow of nurses leaving the profession. Without replacements available, as is already the case in many OECD countries, the healthcare sector and therefore society's health in general are compromised.

These findings challenge the worth of pursuing any current management practices that negatively impact upon supervisor-subordinate communication relationships by increasing managerial autonomy and decreasing the discretionary power of nurses (by increasing accountability, and in turn significantly increasing their workloads) (Buchan and Calman, 2004; Buchanan and Considine, 2002). These combined conditions appear to have led to increased supervisor ambiguity, which has negatively impacted upon the affective commitment of nurses. This is a major concern for managers regarding retaining those healthcare workers in short supply, such as nurses and doctors, because previous research has identified the significant relationship between organisational effectiveness and turnover (Goris, et al., 1997; Petty, McGee and Cavender, 1998). Further, according to Drucker (2006) and Covey (2006), control management practices traditionally used in bureaucratic organisations are not congenial for retaining professionals whose skills and knowledge provide them with greater employment alternatives. The implementation of recent reforms aimed at increasing managerial power and curtaining professionals such as nurses' levels of discretionary power were expected to deliver efficiency gains for government and 
public sector organisations. However, the proponents of such policies are silent in identifying the cost of these policies in terms of low levels of role clarity. These factors are probably contributing to the high turnover of nurses (Buchan and Calman, 2004; Fitzgerald, 2002). The findings from this paper underline the crucial need to examine and improve current supervision practices in the healthcare sector so that nurses can contribute more effectively to servicing the health of the public.

\section{CONCLUSION}

Using the LMX lens, these findings provide a picture of the state of supervisorsubordinate communication relationships in Australia, and the resultant perceptions of nurse autonomy. The findings indicate that present management practices are not ideal for promoting the very workplace relationships linked to increasing nurses' affective commitment.

The message for managers must be to promote the development of empowering NUM-nurse communication relationships. For all employees, but particularly for professionals such as nurses, not only will they be more productive (because they will suffer less supervisor ambiguity), but high quality NUM-nurse communication relationships are also likely to enhance their perceptions of autonomy and thereby, encourage their commitment to their organisation. These same factors are also likely to encourage them to remain. 


\section{REFERENCES}

Ackroyd, S., Kirkpatrick, I. and Walker, R. (2007) 'Public management reform in the UK and its consequences for professional organization: A comparative analysis', Public Administration, 85 (1), 9-26.

Ahn, J. (2002) ' Beyond single equation regression analysis: Path analysis and multistage regression analysis', American Journal of Pharmaceutical Education, 66 37-42.

Australian Bureau of Statistics (ABS). (2009) Australia social trends, Catalogue 4102.0. Canberra: Australian Bureau of Statistics.

Brown, L and Barnett, J (2004) 'Is the corporate transformation of hospitals creating a new hybrid healthcare space?' Social Science Medicine 58 427-44

Brunetto, Y. and Farr-Wharton, R. (2006) 'The importance of effective organisational relationships for nurses: A social capital perspective', International Journal of Human Resources and Development, 6 (2/3/4), 232-247.

Brunetto, Y. and Farr-Wharton, R. (2007) 'Comparing the impact of management practices on public sector nurses' and administrative employees' commitment to the organisation', Asian Pacific Journal of Health Management, 2 (1), 1734.

Brunetto, Y., Farr-Wharton, R., and Shacklock, K (2011) 'Using the Harvard HRM model to conceptualise the impact of changes to supervision upon HRM outcomes for different types of public sector employees', International Journal of Human Resource Management 22 (3) 553-73.

Brunetto, Y., Farr-Wharton, R., and Shacklock, K (2010) 'The impact of supervisorsubordinate relationships on morale: Implications for public and private sector nurses' commitment', Human Resource Management Journal 20 (2) 206-225.

Buchan, J. (1999) 'Still attractive after all these years? Magnet hospitals in a changing healthcare environment', Journal of Advanced Nursing, 30 (1), 373-384.

Buchan, J. and Calman, L. (2004) 'The global shortage of registered nurses: An overview of issues and Actions'. International Council of Nurses, Geneva

Buchanan, J. and Considine, G. (2002) '"Stop telling us to cope" NSW nurses explain why they are leaving the profession,. A Report for the NSW Nurses Association'. Australian Centre for Industrial Relations Research and Training, University of Sydney Press, Sydney

Cole, M. S., Schaninger, W. S. and Harris, S. G. (2002) 'The workplace social exchange network: A multilevel, conceptual examination', Group and Organization Management, 27 142-167.

Conger, J. A. and Kanungo, R. A. (1988) 'Behavioral dimensions of charismatic leadership'. In (Eds, Conger, J. A. and Kanango, R. N.) Charismatic leadership: The elusive factor in organizational effectiveness Jossey-Bass, San Francisco, CA, pp. 78-97.

Evetts, J. and Buchner-Jeziorska, A. (1997) 'Professionalism in European markets: The International Order of Engineering in the UK and Poland', Policy Studies 18 (3), 239-249.

Ferlie, E., Pettigrew, A., Ashburner, L. and Fitzgerald, L. (1996) The New Public Management in Action., Oxford University Press, Oxford.

Fisher, R., Maltz, E., Jaworski, B. (1997). "Enhancing communication between marketing and engineering: The moderating role of relative functional identification." Journal of Marketing 61(3): 54-70.

Fitzgerald, D. (2002) 'Nurse shortage: A crisis for the next decade', Contemporary Nurse, 13 (2and3), 209-212. 
Gee, C (2007) The Contribution of the Australian Private Hospitals Sector Asia Pacific Journal of Health Management 2 (1) 41-46

Gerstner, C. and D. Day. 1997. 'Meta-analytic review of leader-member exchange theory: Correlates and construct issues.' Journal of Applied Psychology 82, 827-844.

Ghauri, P. and Grønhaug, K. (2002) Research methods in business studies: A practical guide, Financial Times Prentice Hall, Harlow, UK.

Gleeson, D and Shain, F (1999) Managing ambiguity: between markets and managerialism -case study of 'middle' managers in further education, Sociological Review 47(3) pp461-490

Gomez, C. and Rosen, B. (2001) 'The leader member exchange as a link between managerial trust and employee empowerment', Group and Organisational Management, 26 (1), 53-69.

Goris, J., Vaught, B. and Pettit, J. (2000) 'Effects of communication direction on job performance and satisfaction: A moderated regression analysis', Journal of Business Communication, 37 (4), 348-368.

Graen, G. and Uhl-Bien, M. (1995) 'Relationship-based approach to leadership: Development of leader-member exchange (LMX) theory of theory over 25 years: Applying a multi-level multi-domain perspective', Leadership Quarterly, 6 (2), 219-247.

Graen, G. B. and Scandura, T. (1987) 'Towards a psychology of dyadic organizing'. In (Eds, Cummings, L. L. and Staw, B.) Research in organizational behavior, Vol. 9 JAI Press, Greenwich, CN:. pp. pp. 175-208.

Grapentine, T. (2000) 'Path analysis vs. structural equation modeling', Marketing Research,, 12 (3), 13-20.

Gray, A. and Phillips, V. (1994) 'Turnover, age and length of service: A comparison of nurses and other staff in the National Health Service ', Journal of Advanced Nursing J19 (4), 819-827.

Gray, J, and Laidlaw, H 2002, 'Part-time employment and communication satisfaction in an Australian retail organization', Employee Relation, vol. 24, no. 1/2, pp. 211218.

Haskins, W. (1996) 'Freedom of speech: Construct for creating a culture which empowers organisations members', Journal of Business Communication, 33 (1), 85-89.

Johlke, M. and Duhan, D. (2000) 'Supervisor communication practices and service employee job outcomes', Journal of Services Research, 3 (2), 154-165.

Kacmar, K., Witt, L., Zivnuska, S., Gully, S. (2003). "The interactive effect of leadermember exchange and communication frequency on performance ratings."

Kirkpatrick, I. and Ackroyd, S. (2003) 'Transforming the professional archetype? The new managerialism in UK social services', Public Management Review, 5 (4), 511-531.

Larsen, A-C. (2005) 'In the public interest: autonomy and resistance to methods of standardising nurses' advice and practices from a health call centre in Perth, Western Australia'. Nursing Inquiry, 12 (2), 135-143.

Laschinger, H. and Wong, C. (1999) 'Staff nurse empowerment and collective accountability: Effect on perceived productivity and self-rated work effectiveness', Nursing Economics, 17 (6), 308-316.

Mayfield, J and Mayfield, M 2002, 'Leader communication strategies - critical paths to improving employee commitment', American Business Review, vol. 20, no. 2, pp. 89-94 
Mueller, B. and Lee, J. (2002) 'Leader-member exchange and organizational communication satisfaction in multiple contexts', Journal of Business Communication, 39 (2), 220-244.

Newman, K., Maylor, U. and Chansarkar, B. (2002) 'The nurse satisfaction. Service quality and nurse retention chain: Implications for management of recruitment and retention', Journal of Management in Medicine, 16 (4/5), 271-292.

OECD. (2005). Maintaining a prosperous society: Ageing research report. Geneva: Organisation for Economic Co-operation and Development.

Palese, A., Pantali, G., \& Saiani, L. (2006). The management of a multigenerational nursing team with differing qualifications: A qualitative study. The Health Care Manager, 25(2), 173-193.

Petty, M., McGee, G. and Cavender, J. (1998) 'A meta-analysis of the relationships between individual performance', Academy of Management Review 9(4), 71221

Productivity Commission (2005) 'Australia's Health Workforce'. Productivity Commission, Commonwealth of Australia, Canberra

Rhoads, G. K., Singh, J. and Goodell, P. W. (1994) 'The multiple dimensions of role ambiguity and their impact upon psychological and behavioural outcomes of industrial salespeople', Journal of Personal Selling and Sales Management 14 $1-22$.

Robinson, S., Murrells, T. and Clinton, M. (2006) 'Highly qualified and highly ambiguous: Implications for workplace retention of realizing the career expectations of graduate nurses in England', Human Resource Management Journal, 16 (3), 287-312.

Secombe, I. and Smith, G. (1997) Taking part: Registered nurses and the labour market in 1997, Grantham Book Services, Grantham, England.

Seibert, S., Silver, S. and Randolph, W. (2004) 'Taking empowerment to the next level: A multiple-level model of empowerment, performance, and satisfaction', Academy of Management Journal, 47 332-349.

Sparrowe, R. and Linden, R. (1997) 'Process and structure in leader-member exchange', Academy of Management Journal, 22 (2), 522-552.

Spector, P. E. (1994) 'Using self-reported questionnaires in OB research: A comment on the use of a controversial method', Journal of Organisational Behavior, 15 (5), 385-392.

Spreitzer, G. (1995) 'Psychological empowerment in the workplace: Dimensions, Measurement and Validation', Academy of Management Journal, 38 (5), 14421465.

Spreitzer, G. (1996) 'Social Structural Characteristics of Psychological Empowerment', Academy of Management Journal, 39 (2), 483-504.

Thompson, C. A. and Prottas, D. J. (2006) 'Relationships among organisational family support, job autonomy, perceived control, and employee well being', Journal of Occupational Health Psychology, 11 (1), 100-118.

Wayne, S., Shore, L. and Linden, R. (1997) 'Perceived organisational support and leader exchange: A social exchange perspective', Academy of Management Journal, 40 (1), 82-111.

Yrie, A., Hartman, S. and Galle, W. (2003) 'Examining communication style and leader-member exchange: considerations and concerns for managers', International Journal of Management 20 (1), 92-100. 
TABLES

TABLE 1: Demographics of the sample

\begin{tabular}{lc}
\hline & $\begin{array}{c}\text { Nurses } \\
(\mathrm{N}=900)\end{array}$ \\
\hline GENDER: & $33(3.7 \%)$ \\
Male & $867(96.2 \%)$ \\
Female & \\
AGE: & $74(8.2 \%)$ \\
$<30$ years & $339(37.7 \%)$ \\
30 - 45 years & $487(54.1 \%)$ \\
$>45$ years & \\
\hline
\end{tabular}


TABLE 2 Nurse Correlations and Cronbach's Alpha Reliability

Variable

Mean Stand

Deviat.

1. Location (control) 1

2. Supervisor-subordinate $\begin{array}{llll}3.948 & 1.03 & -.013 & 1\end{array}$

$(.803)$

communication

relationship

3. Supervisor Ambiguity $4.534 \quad 1.298 \quad-.014 \quad .58 * * \quad 1 \quad$ (.905)

$\begin{array}{lllllllll}\text { 4. Autonomy } & 4.389 & .918 & .029 & .24 * * & .28 * * & 1 & \mathbf{( . 8 9 5 )}\end{array}$

$\begin{array}{llllllll}\text { 5. Affective Commitment } & 4.056 & 1.237 & .056 & .43^{* *} & .38^{* *} & .34^{* *} & 1 \text { (.87) }\end{array}$

\footnotetext{
${ }^{\mathrm{a}} \mathrm{N}=900$. Numbers in parentheses on the diagonal are the Cronbach's alpha coefficients of the composite scales.

** Significant at the 0.01 level (2-tailed).

* Significant at the 0.05 level (2-tailed).
} 
TABLE 3 Regression analysis detailing relationship between supervisorsubordinate communication relationship and supervisor ambiguity Independent Variable

Supervisor ambiguity

$\beta$

Supervisor-subordinate communication

relationship

$\mathrm{F}$

$\mathrm{R}^{2}$

* Significant at the 0.001 level (2-tailed).
$.58^{*}$

$1425.8^{*}$

$61.4 \%$ 
TABLE 4 Regression analysis detailing relationship between supervisor ambiguity and autonomy

\begin{tabular}{lc}
\hline Independent Variable & Autonomy \\
& $\boldsymbol{\beta}$ \\
\hline Supervisor Ambiguity & $.276^{*}$ \\
F & $73.766^{*}$ \\
$\mathrm{R}^{2}$ & $7.6 \%$
\end{tabular}

* Significant at the 0.001 level (2-tailed). 
TABLE 5 Regression analysis detailing relationship between autonomy and affective commitment Independent Variable Affective Commitment $\boldsymbol{\beta}$

\begin{tabular}{lc}
\hline Autonomy & $.34 *$ \\
$\mathrm{~F}$ & $117.9 *$ \\
$\mathrm{R}^{2}$ & $11.6 \%$ \\
\hline
\end{tabular}

* Significant at the 0.001 level (2-tailed). 
TABLE 6 Regression analysis detailing relationship between supervisorsubordinate communication relationship, supervisor ambiguity, discretionary power and affective commitment

Independent Variables

\section{Affective Commitment}

$\boldsymbol{\beta}$

Supervisor-subordinate communication

$.334^{*}$

relationship

Supervisor Ambiguity $\quad .047$

Autonomy .246*

$\mathrm{F}$

97.384

$\mathrm{R}^{2}$

$24.6 \%$

* Significant at the 0.001 level (2-tailed). 